\title{
Livros didáticos brasileiros e as ideias sobre direitos humanos, paz e pacifismo $(1940-2000)^{1}$
}

\author{
Décio Gatti Júnior \\ Universidade Federal de Uberlândia \\ Giseli Cristina do Vale Gatti \\ Universidade de Uberaba
}

\section{Resumo}

Este artigo visa conhecer os valores pacifistas contidos em livros didáticos brasileiros entre 1940 e 2000. Livros que, segundo Chervel (1990), são portadores de finalidades educacionais. Foram analisadas obras referentes à História Geral e do Brasil, à Educação Moral e Cívica e à Organização Social e Política do Brasil (OSPB). Constatou-se que, entre 1940 e 1970, conjugavam-se ideário liberal e formação moral cristã. Na década de 1980, houve iniciativas originais na disciplina de OSPB. Nas décadas de 1990 e 2000, apesar de maior adesão à Doutrina do Direitos Humanos e à Educação para a Paz, houve enfraquecimento da temática nos livros didáticos.

Palavras-chave: Livro didático. Direitos humanos. Educação para a paz.

\section{Brazilian textbooks and ideas on human rights, peace and pacifism (1940-2000)}

\section{Abstract}

The purpose of this article is to discern the pacifist values contained in Brazilian textbooks from 1940 to 2000. According to Chervel (1990), these books have an educational aim. Works were analyzed concerning general history, history of Brazil, moral and civic education, and social and political organization of Brazil (SPOB). It was observed that from 1940 to 1970, a liberal ideology joined christian moral training. In the 1980s, there were original initiatives in the school subject of SPOB. In the 1990s and 2000s, in spite of greater adherence to the doctrine of human rights and education for peace, there was weakening of the theme in textbooks.

Keywords: School textbooks. Human rights. Education for peace. 


\section{Libros de texto brasileños y las ideas sobre derechos humanos, paz y pacifismo $(1940-2000)$}

\section{Resumen}

En el artículo se exponen los valores pacifistas contenidos en los libros didácticos de entre 1940 y 2000. Libros que, según Chervel (1990), son portadores de finalidades educativas. Fueron analizadas obras sobre historia general y de Brasil, sobre educación moral y cívica y sobre organización social y política de Brasil (OSPB). Se constató que, entre 1940 y 1970, se conjugaban el ideario liberal y la formación moral cristiana. En la década de 1980, hubo iniciativas originales en la asignatura de OSPB. En las décadas de 1990 y 2000, a pesar de mayor adopción a la doctrina de los derechos humanos y a la educación para la paz, se nota debilitamiento de esta temática en los libros didácticos.

Palabras-clave: Libro de texto. Derechos humanos. Educación para la paz.

\section{Introdução}

As finalidades ideais propostas para a educação de uma localidade, estado ou país, conforme o caso, podem ser examinadas, sobretudo, nas concepções educacionais veiculadas em uma época, mediante o conhecimento das ideais de intelectuais disseminadas por meio de livros e de artigos ou mesmo de entrevistas veiculadas em jornais e revistas; nas diferentes legislações e normas do ensino escolar estabelecidas em âmbito estatal, confessional ou da sociedade civil; nas iniciativas de formação e de treinamento de docentes, em especial, nos momentos de reformas educacionais mais amplas; na produção de manuais e de livros didáticos destinados às escolas de um município, de uma estado ou mesmo de uma nação?

Nesta direção, é notável perceber os esforços das autoridades constituídas com maior ou menor legitimidade no Brasil durante o Século XX, em especial no âmbito estatal, para fixar e administrar o conteúdo disseminado no âmbito escolar, em especial, na formação de adolescentes e de jovens nas instituições escolares nacionais. Esforços que envolveram com viva intensidade 
o controle sobre a produção e sobre o conteúdo veiculado nos manuais e livros escolares ${ }^{3}$.

A partir desses pressupostos, efetivou-se a pesquisa no âmbito da História das Disciplinas Escolares que originou o presente texto, na qual os objetos privilegiados foram os conteúdos relacionados à promoção da doutrina dos direitos humanos, da paz e de valores pacifistas entre os adolescentes e jovens presentes nos livros didáticos utilizados nas escolas brasileiras, no período histórico compreendidos pelas décadas de 1940 e de 2000, cujos marcos temporais são, quanto ao início: a promulgação da nova constituição brasileira (1946), seguida pela aprovação da Declaração Universal dos Direitos Humanos, pela Organização das Nações Unidas (1948). Quanto ao final: a promulgação de uma nova constituição brasileira (1988), seguida pela nova Lei de Diretrizes e Bases da Educação (1996) e pelos Parâmetros Curriculares Nacionais (publicados desde 1998).

Do referido período, consta publicado um considerável número de livros didáticos escolares que, no caso brasileiro, ocupam lugar central na produção editorial nacional e são veículos praticamente exclusivos da formação cultural de milhares de adolescentes e de jovens nas escolas, sendo que, na presente análise, foram observados os conteúdos relacionados à doutrina dos Direitos Humanos e à Educação para a Paz, presentes em obras ou coleções didáticas de grande circulação no país, o que incluiu, principalmente, a disciplina de "Educação Moral e Cívica", mas também, outras disciplinas escolares, a saber: "Estudos Sociais", "História Geral" e "Organização Social e Política do Brasil".

\section{Dos livros de História Geral aos de Educação Moral e Cívica (1940/1960)}

De modo geral, a construção de uma sociedade de direitos, afinada com os princípios contidos na Declaração Universal dos Direitos Humanos de 1948 não tem sido uma tarefa fácil, dados os momentos em que as nações separadamente ou em conjunto preconizam ações que afrontam com maior ou menor intensidade seus princípios. Porém, o texto da própria Declaração de 1948 solicita às nações que "[...] tendo sempre em mente esta Declaração, 
se esforce, através do ensino e da educação, por promover o respeito a esses direitos e liberdades [...]" (ONU, 1948, p. 4).

Neste sentido, a Constituição brasileira de 1946 já contemplava pontos importantes dos direitos fundamentais, tais como o respeito à separação dos poderes, respeito à lei, mas também aos direitos sociais, tais como a ordem econômica baseada no princípio da justiça social e a educação como um direito de todos. Além disso, asseverava, a partir da melhor tradição liberal, que "Todo poder emana do povo e em seu nome será exercido" (CONSTITUIÇÃO DOS ESTADOS UNIDOS DO BRASIL, 1946, p. 1).

De modo geral, os manuais escolares brasileiros de História Geral das décadas de 1950 e 1960 seguiam, rigorosamente, o Programa de História Geral determinado pelo governo federal (Portaria n 966, de 2 outubro 1951 e Portaria $n^{\circ}$ 1045, de 14 dezembro de 1951). Nelas, o conteúdo afeto aos direitos humanos não ganhava centralidade, aparecendo, ocasionalmente, nas unidades de ensino referentes às revoluções do século XVIII, em especial, na temática da Independência dos Estados Unidos da América, da Revolução Francesa, mas também, em um capítulo específico, presente em várias cole221 ções didáticas, acerca das democracias americanas, seus maiores vultos e episódios, com destaque para o papel desempenhado pelos Estados Unidos da América e pela França, com predomínio do tom informativo e laudatório.

Em 4 de julho de 1776 o congresso da Filadélfia reconhecia a independência precedida da Declaração de Direitos redigido por Thomas Jefferson. Proclamava-se a "igualdade originária dos homens" e seu direito absoluto "à vida, à liberdade, aos meios de adquirir e de conservar a propriedade, de alcançar a felicidade e a segurança". Nasciam assim os Estados Unidos da América do Norte, pioneiros do liberalismo fundado nos sãos princípios da democracia (MELLO; [SILVA]; GARCIA, 1950, p. 146).

Em fins de agosto a Assembleia votou a Declaração dos Direitos do Homem e do Cidadão, em que estão consubstanciados os princípios em nome dos quais foi feita a Revolução e que são chamados "princípios de 89". Estabelecem eles a soberania do povo, a igualdade de todos perante a lei, a garantia do direito de propriedade, a liberdade de imprensa e a liberdade de religião (SOUZA, 195 I, p. 124). 
Com a Independência dos Estados Unidos da América criou-se o primeiro estado soberano na América. $\bigcirc$ regime democrático que adotaram e a forma federativa em que se constituíram as antigas colônias, agora independentes, constituíram organização original. Sua constituição votada solenemente num congresso nacional, em 1787, representava a realização prática dos novos princípios políticos e sociais dos pensadores dos séculos XVII e XVIII. Os soldados franceses que lutaram ao lado de Washington levaram para a Europa a influência do novo espírito democrático que puderam observar (MATTA, 1956, p. 141).

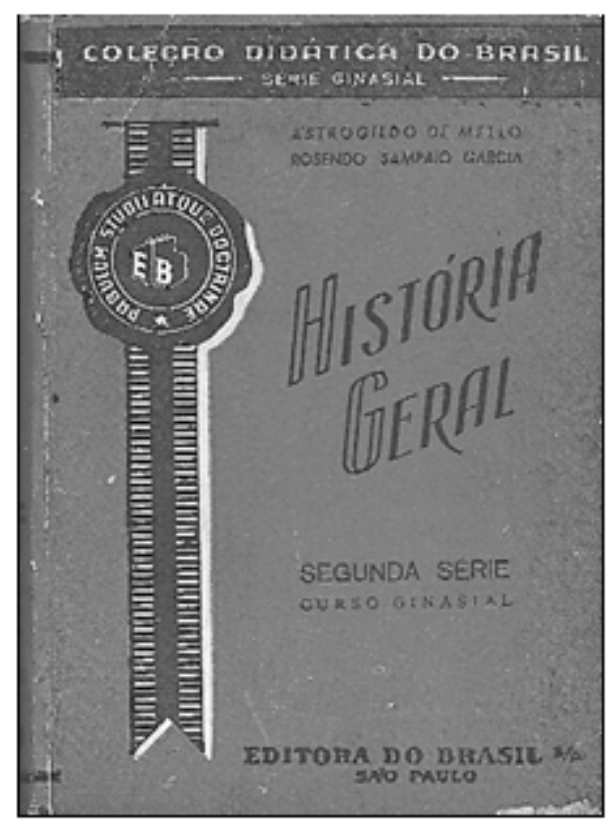

Capa da $7^{a}$ edição da obra intitulada História geral (Segunda série, curso ginasial), com autoria de Astrogildo de Mello, [Raul de Andrade e Silva] e Rosendo Sampaio Garcia. São Paulo: Editora do Brasil, 1950. 


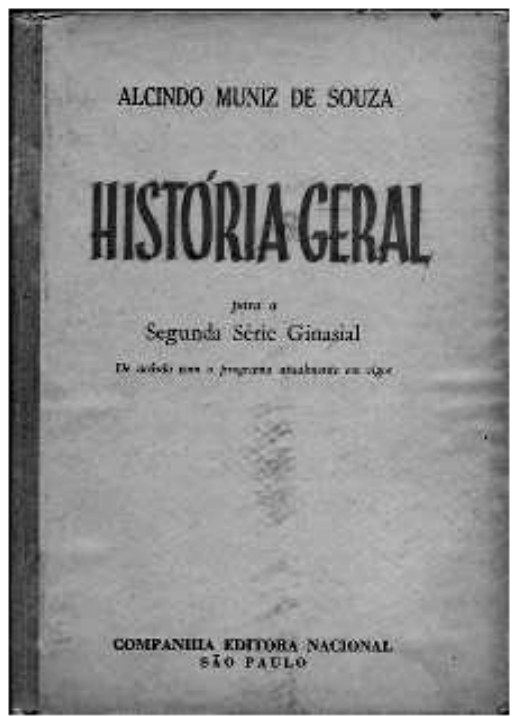

Capa da $13^{a}$ edição da obra intitulada História geral para a segunda série ginasial, com autoria de Alcindo Muniz de Souza. São Paulo: Companhia Editora Nacional, 1951.

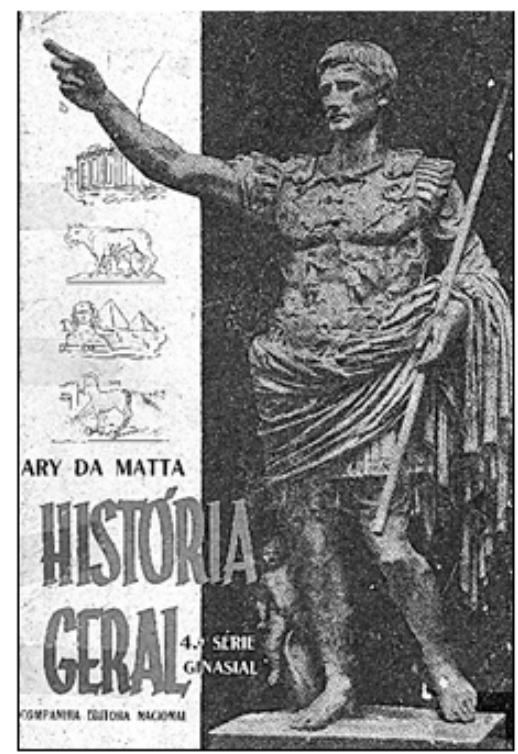

Capa da $3^{a}$ edição da obra intitulada História geral (História moderna e contemporânea, $4^{a}$. série ginasial), com autoria de Ary da Matta. São Paulo: Companhia Editora Nacional, 1956. 
Em texto de Victor Mussumeci (1959), além de ser solicitado que os alunos elaborassem biografias de Benjamin Franklin, Thomas Jefferson, John Adams, Alexander Hamilton, George Washington e Marquês de Lafayette, também consta, na íntegra, a Declaração dos Direitos do Homem e do Cidadão de 1789.

Em outra frente, ainda que não depositasse, na abordagem dos fatos históricos, sua ênfase, os livros de Educação Moral e Cívica traziam conteúdos afetos à questão dos direitos humanos, da paz e do pacifismo com maior intensidade e regularidade que os de História Geral e de História do Brasil.

A "Pequena Enciclopédia de Moral e Civismo", publicada originariamente em 1967, pela Campanha Nacional do Material de Ensino, vinculada ao Departamento Nacional de Educação do Ministério da Educação e Cultura, teve grande circulação no Brasil. A elaboração ficou a cargo do Padre Fernandes Bastos de Ávila, professor de Introdução à Sociologia, Teoria Sociológica Contemporânea e de Doutrina Social da lgreja na Escola de Sociologia e Política da Pontifícia Universidade Católica do Rio de Janeiro. Trecho contido no verbete "Democracia" interessou de modo particular, pois demonstrava a percepção da defesa de uma programática religiosa na agenda política da época, conforme se pode depreender do texto a seguir.

A democracia cristã objetiva uma organização política do Estado que melhor assegure a realização da concepção cristã do homem e da sociedade. Nascida principalmente de uma reação aos regimes totalitários, pode vir a reencontrar as grandes correntes de fundo que a canalizam, para além dos sistemas e das ideologias, as grandes e indestrutíveis aspirações da humanidade (ÁVILA, 1967, p. 145).

Essa tendência já percebida é confirmada em outros textos de Educação Moral e Cívica, nos quais aparecem temáticas como "As Maravilhas da Criação" e "O Problema de Deus"4. Porém, nessa obra, há espaço para disseminação de conteúdos que se referem ao papel das Nações Unidas e à defesa da democracia como regime de poder, com destaque para um capítulo intitulado "Os perigos que ameaçam a democracia", nomeadamente: a Demagogia, a Ditadura e o Comunismo. É interessante observar que os autores não vejam nenhum problema em relação ao governo brasileiro ser exercido 
sem voto direto e universal, considerando, no entanto, que o maior problema do país fosse o "desenvolvimento".

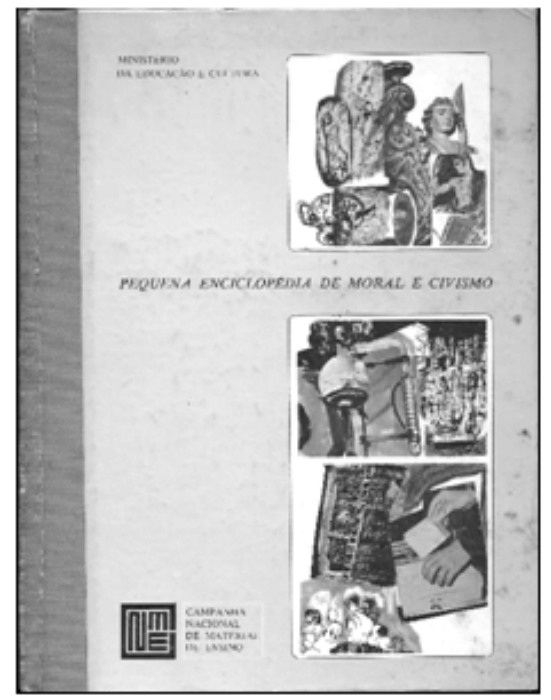

Capa da obra intitulada Pequena Enciclopédia de moral e civismo, com autoria do Padre 225 Fernandes Bastos de Ávila, S. J., publicada no Rio de Janeiro, pelo Ministério da Educação e Cultura, 1967.

Ainda na já mencionada "Pequena Enciclopédia de Moral e Civismo", há dois verbetes de particular interesse para os propósitos deste texto, paz e pacifismo com o seguinte conteúdo:

PAZ. Do latim 'pax, pacis'. Os antigos definiam a paz como tranqüilidade da ordem. A noção ainda hoje é válida, desde que haja acôrdo a respeito do conceito de ordem. Pela expressão 'tranquillitas, odinis queriam entender uma sensação difusa e profunda de euforia resultante de uma perfeita ordenação dos elementos de um todo. A paz é aspiração fundamental de cada homem e de toda humanidade, a ponto de seu conceito quase se confundir com o de felicidade. Ela tem uma dimensão interna, moral e psíquica, e uma dimensão externa, social. A plenitude da paz interna o homem só atinge quando consegue a ordenação de suas potencialidades em torno de um ideal digno de ser vivido. Só esta paz é durável; não se altera com as lutas e tribulações da vida, porque não se confunde com fases transitórias de euforia que experimentamos, por vêzes, por ocasião da recuperação da saúde ou da realização 
de um bom negócio. Por outro lado, a paz social só pode resultar de um relacionamento entre pessoas, grupos e nações, fundado na justiça, na lealdade e no amor. Só êste relacionamento constitui propriamente uma ordem, no qual é a paz é a resultante mais autêntica. Antes, as elites políticas, culturais e financeiras viviam numa paz aparente, porque supunham ou procuravam convencer-se de que a condição miserável das massas fazia parte inexorável de uma ordem universal e imutável. Hoje, a humanidade vem aprendendo, a duras penas, que enquanto existir fome e miséria, persistirá uma desordem radical, fruto do egoísmo dos indivíduos, dos grupos e das nações, sôbre a qual é impossível conquistar uma paz duradoura. A evolução da humanidade chegou a um ponto no qual a paz social ou é universal ou é impossível. Não poderá haver paz, enquanto não houver, para todos, condições concretas para atingir níveis de vida compatíveis com a dignidade humana. Não poderá haver paz construída sôbre a frustação de milhões de sêres humanos iguais em dignidade e que desfrutam de todos os requintes da cultura. Cresce, na humanidade, a consciência desta verdade, e por isso vemos que se multiplicam os organismos supra nacionais voltados não tanto para impor um falsa paz pela força, mas combater as causas radicais da intranqüilidade que são a iniqüidade social, a injustiça na participação das riquezas, numa palavra, a desordem (AVILA, 1967, p. 376).

PACIFISMO. Da raiz latina "pax, pacis" = paz. É um movimento e uma doutrina. Como movimento teve origem nos Estados Unidos, com a fundação, em 1828, do American Peace Society, que fundiu um grande número de sociedades estaduais, do mesmo gênero, criados sob a inspiração de David Dodge. $\bigcirc$ movimento difundiu-se ràpidamente no mundo com o objetivo de criar condições psicológicas e políticas para uma paz perpétua. A seu crédito, parcialmente, se inscreve a criação de dois institutos beneméritos para solução pacífica de conflitos internacionais: a Arbitragem e a Côrte Internacional de Justiça, com sede em Haia. Para criação da Liga das Nações, após a Primeira Guerra Mundial, com o objetivos pacifistas influiu poderosamente a pressão exercida pelo movimento sôbre o presidente Wilson. Sua influência não deixou de se fazer sentir, também, na criação da $\mathrm{N}$ U. Como doutrina, o pacifismo se caracteriza pela exaltação da paz e a condenação incondicional do uso da violência com fundamento teórico na unidade do gênero humano e na inviolabilidade da vida humana. Condena assim, qualquer tipo de guerra, mesmo a defensiva, baseada na idéia de que, assim como os indivíduos não podem fazer justiça por suas mãos, assim também os Estados agredidos devem esperar 
a justiça de uma organização internacional, capaz de fazê-la sem violência. Considera que o único meio eficaz para garantir uma paz inviolável é o advento de uma sociedade universal sem pátrias e sem diversidades religiosas ou ideológicas (cosmopolitismo). $\bigcirc$ pacifismo, entretanto, que não deve ser confundido com determinadas campanhas pacifistas com fins exclusivamente políticos e estratégicos cede hoje lugar a um internacionalismo mais realista, que aceita a premissa histórica de uma cultura pluralista e visa ao objetivo da paz, não pela supressão das diversidades, mas pelo senso de solidariedade universal, mantido entre grupos e nações por uma Organização que disponha de meios eficazes para garanti-la (ÁVILA, 1967, p. 368).

Nessa linha argumentativa, é interessante observar conteúdo expresso na obra de Felipe Moschini, Otto Costa e Victor Mussumeci, intitulada "Moral e Civismo: Ensino de Primeiro Grau", de 1970, publicada pela Editora do Brasil e destinada às classes da $8^{a}$ Série do $1^{\circ}$ Grau. Nela pode-se ler:

A paz sempre foi um profundo anseio de toda Família Humana, em todas as épocas da História. Essa paz tão suspirada é obra da justiça e fruto da ordem. Ela não significa, absolutamente, a mera ausência de guerra, o simples equilíbrio de forças entre as potências, e, muito menos, ela não é o resultado da opressão violenta (MOSCHINI, COSTA; MUSSUMECI, 1970, p. 76).

a) $\mathrm{A} O N U$ é uma organização integral para a paz e para a segurança mundiais: conta com órgãos políticos, jurídicos, econômicos e sociais.

b) Fica proibida entre os membros da ONU qualquer espécie de guerra.

$[\ldots]$

d) Insiste-se mais na prevenção do que na repressão da guerra. A organização pretende ser mais eficaz evitando a guerra do que admitindo-a, para depois solucionar suas sequelas (MOSCHINI, COSTA; MUSSUMECl, 1970, p. 94-5). 


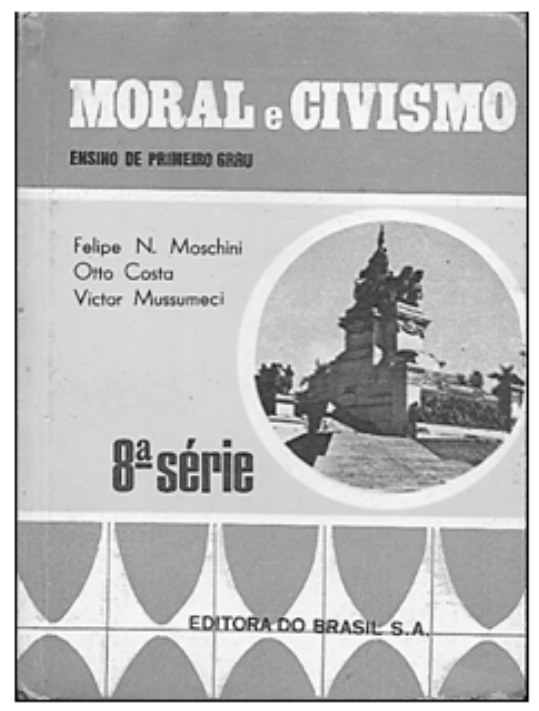

Capa da obra intitulada Moral e Civismo: Ensino de Primeiro Grau (8ª . Série), de autoria de Felipe Moschini; Otto Costa e Victor Mussemeci, publicada em São Paulo, pela Editora do Brasil, 1970.

Em 1971, houve publicação de nova edição do livro de Educação, Moral e Cívica de João Camilo de Oliveira Tôrres, agora com o subtítulo "Organização Política do Brasil pela Constituição de 1969". Nele, além dos conteúdos das edições anteriores, consta da décima lição um capítulo com justificativa para a Revolução de Março de 1964, com explicações sobre a nova ordem jurídica geral (Constituições de 1967 e 1969). Para ele,

Encaminhando-se o País para uma crise que transparecia levá-lo a rumos destoantes com as nossas tradições democráticas e cristãs, a disciplina nas fôrças armadas deteriorando-se ràpidamente com beneplácito do governo, alguns chefes militares responsáveis reagiram e, afinal, por fôrça de um movimento partido de Minas e articulado no Rio, foi instaurado no País novo sistema político (TÔRRES, 1971, p. 101).

No que diz respeito ao ensino de Educação Moral e Cívica para os estudantes de nível médio ( $2^{\circ}$. Grau), foi possível examinar duas tendências diferentes na educação escolar, conforme apontam os conteúdos de dois manuais escolares do final da década de 1970. No primeiro, permanece uma 
tônica religiosa no encaminhamento das questões morais, conforme pode ser exemplificado na visão de liberdade expressa em seu conteúdo.

É preciso entender o exercício da liberdade como um roteiro de realização de valores. No ponto mais alto da escala de valores, encontra-se Deus. Seus lampejos na alma do homem são a inteligência e a consciência moral. Graças a estes dons, pode o homem motivar racionalmente suas preferências. De sua parte, as preferências racionais transformam o uso da liberdade em ação criadora, sob inspiração do amor. Ora, o amor é sublimação da responsabilidade. Liberdade com Deus é liberdade inspirada no amor. Liberdade com Deus é o mais alto ideal de aperfeiç,oamento do exercício da liberdade com responsabilidade (SILVA; CUNHA, 1977, p. 391.

Na segunda obra analisada (LUCCl, 1979), predomina a abordagem laica. Porém, há novo formato didático, com emprego do estudo dirigido em todo o texto, especialmente por meio da estratégia de preenchimento de lacunas. É enfatizada a existência de órgãos internacionais, tais como: as Nações Unidas, a Organização dos Estados Americanos, o Banco Interamericano de 229 Desenvolvimento etc., bem como consta a íntegra do texto da Declaração Universal dos Direitos Humanos de 1948.

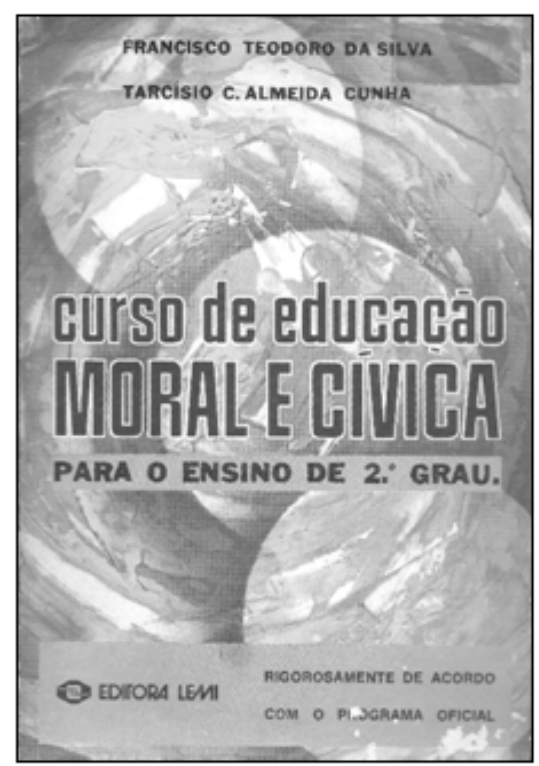


Capa da $7^{a}$ edição da obra intitulada Curso de Educação Moral e Cívica (para o ensino de $2^{\circ}$. Grau), com autoria de Francisco Teodoro da Silva e Tarcísio C. Almeida Cunha, publicada em Belo Horizonte, pela Editora Lemi, 1977.

Ainda no que se refere, especificamente, ao tema do pacifismo, é interessante observar as ideias sobre os princípios básicos da política exterior brasileira contida no "Curso de Educação Moral e Cívica para o Ensino de $2^{\circ}$. Grau", de autoria de Silva e Cunha, onde se pode ler:

4. As condições características do Brasil determinam o comportamento internacional. Fixaram-the, por assim dizer, o caráter, assim, como as qualidades pessoais caracterizam os homens e thes determinam o comportamento social. Os princípios básicos da política exterior do Brasil, coerentes com a formação nacional, podem ser enumerados: a) o pacifismo; b) a igualdade das nações; c) independência nacional; d) a solidariedade coletiva e o princípio da não intervenção. 5. O PACIFISMO é princípio constitucional. [...] A guerra é recurso extremo, de legítima defesa, $\bigcirc$ Brasil somente se envolveu em guerras para a preservação de sua independência, integridade, honra e segurança (SILVA; CUNHA, 1977, p. 180-1).

Na mesma direção, em obra intitulada "TDMC: Trabalho Dirigido de Moral e Civismo" 5 , destinada ao público escolar de $2^{\circ}$. Grau, publicado pela Editora Saraiva, em 1979, Elian Alabi Lucci, ao tratar das qualidades básicas do caráter do homem brasileiro, ressaltava o individualismo, o sentimentalismo, a adaptabilidade, a improvisação, a hospitalidade, a cordialidade, a comunicabilidade e o pacifismo. Sobre este último, pode-se ler:

[...] o pacifismo, outra característica do povo brasileiro, que você deve ter notado através dos estudos já realizados sobre a nossa vida política, pois tanto internamente como externamente ela foi sempre orientada pelos ideais de paz e harmonia. A nossa independência, por exemplo, se concretizou com pouca luta; a abolição da escravatura também ocorreu de forma pacífica. Pacificamente também passamos do Império à República. Os movimentos revolucionários do início de nossa República tiveram curta duração e quase não causaram mortes (LUCCl, 1979, p. 20-21). 


\section{A emergência dos Estudos Sociais no Ensino Primário /década de 1970)}

Com a emergência da disciplina nomeada Estudos Sociais nos currículos escolares de $1^{\circ}$. Grau na década de 1970, em detrimento das disciplinas de História e de Geografia, houve considerável perda do estudo dos episódios históricos relacionados à construção das declarações de direitos, pois a tônica passa a recair sobre a relação do homem com o meio ambiente; a organização dos municípios, dos estados e do país; o espaço geográfico; o desenvolvimento regional e do país. Apenas, no conteúdo da $8^{a}$. Série, a questão dos direitos humanos teria algum espaço.

Nessa direção, no quarto volume de uma coleção didática de Estudos Sociais do final da década de 1979 (FARIA; DUARTE; MARUM, 1979), referente ao conteúdo destinado à $8^{a}$. Série do $1^{\circ}$. Grau, está presente uma análise do processo de desenvolvimento que levou os Estados Unidos e a União Soviética à designação de grandes potências na década de 1970; a apresentação dos regimes políticos existentes (totalitarismo, socialismo, liberalismo, socialdemocracia); a explicação sobre a forma de organização do 231 Estado brasileiro.

Além disso, houve desenvolvimento de conteúdo referente aos direitos e deveres do cidadão, com diferenciação entre os direitos individuais, sociais e políticos, seguido de comentários sucintos sobre as diversas declarações de direitos. Por fim, foram apresentados direitos presentes no texto constitucional brasileiro em vigor e os deveres dos cidadãos.

Apesar de os Estudos Sociais predominarem nas escolas brasileiras, a existência de livros de História Geral publicados em 1979 e 1980 aponta para a ideia de que os Estudos Sociais não se tornaram hegemônicos nas escolas brasileiras. Exemplo disso é a coleção "Síntese de História" (FARIA; MARQUES, 1979), em seu segundo volume (6". Série do $1^{\circ}$ Grau), apresentava temáticas tais como a constituição do liberalismo como doutrina política, econômica e social, destacando personagens como Locke, Montesquieu, Rousseau, Voltaire; o discurso do presidente americano, no qual consta a frase "[...] para que essa nação, sob a autoridade de Deus, deva renascer em liberdade, e a fim de que o governo do povo, pelo povo e para o povo não pereça na terra" (FARIA; MARQUES, 1979, p. 89). Há também um capítulo de pouca extensão sobre as Nações Unidas'. 


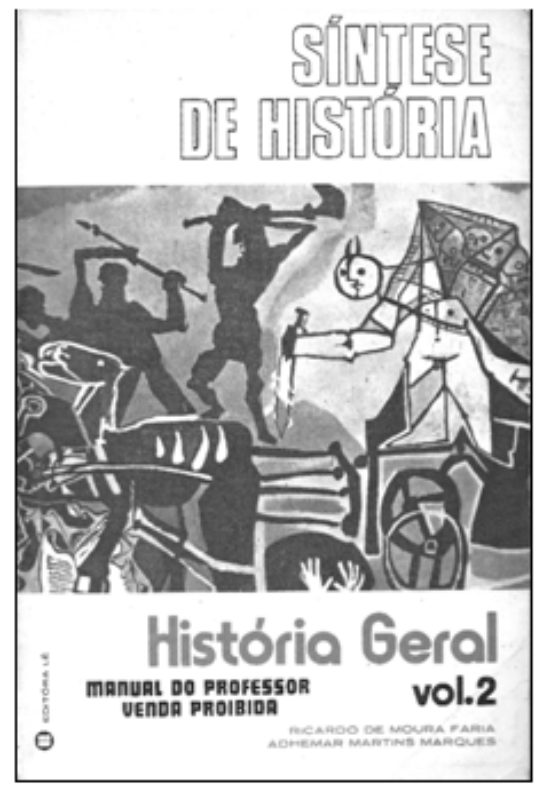

Capa da obra intitulada Síntese de História (v. 2, História Geral), com autoria de Ricardo de Moura Faria e Adhemar Martins Marques, publicado em Belo Horizonte, pela Editora Lê, 1979.

\section{Das alterações de conteúdos na década de 1980 à diluição das décadas de 1990 e de 2000}

Uma alteração digna de nota ocorreu em 1985, durante o processo de redemocratização do Brasil, quando foi publicado o livro "OSPB: introdução à política brasileira", de Frei Betto. Obra de teor extremamente crítico em relação à desigualdade social e ao capitalismo, conforme transparece no texto reproduzido a seguir:

[...] o capitalismo não oferece as mesmas oportunidades a todos. Ele é como um grande funil de cabeça para baixo. Ou uma enorme pirâmide. No pico estreito estão os donos do capital, a pequena minoria que controla as grandes riquezas. No meio está a classe média, os profissionais liberais, conhecidos também pelo nome de pequena burguesia, pois nela se incluem os pequenos 
proprietários. O grande e largo alicerce é integrado pelos trabalhadores, os assalariados da cidade e da zona rural, que só dispõem de sua força de trabalho. Dentro do capitalismo, não se investe no que é necessário à população. Investe-se no que dá lucro [...] (BETTO, 1992, p. 23).

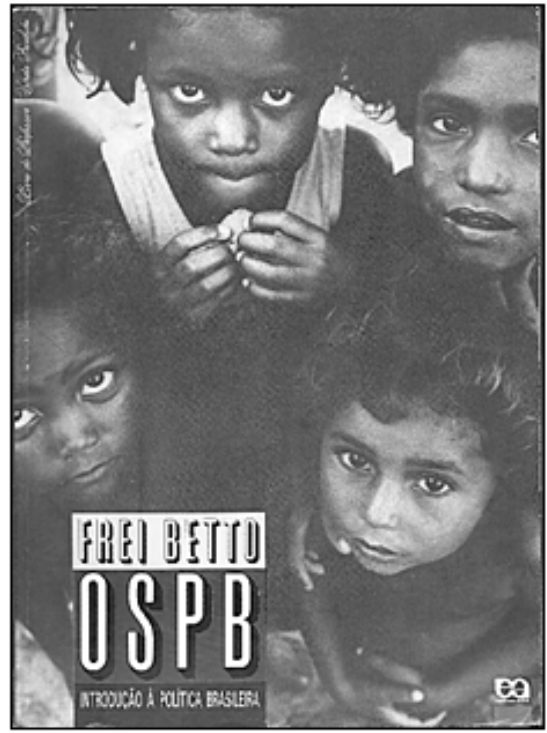

Capa da obra intitulada OSPB: Introdução à Política Brasileira, com autoria de Frei Betto, publicada em São Paulo, pela Editora Ática, 1985.

$\mathrm{Na} 16^{a}$ edição da obra OSPB, de Claudino Piletti, publicada em 1993, com conteúdo totalmente reformulado, de uma obra que vinha sendo publicada desde 1977, aparecem conteúdos detalhados quanto à questão da democracia, das constituições e dos direitos humanos, em especial no capítulo sobre a defesa do cidadão (PILETTI, 1993, p. 76-82). Além disso, aparecem conteúdos sobre a defesa do meio ambiente, direitos das minorias e movimentos sociais. De fato, a perda de densidade na exposição de conteúdos e na apresentação de documentos relacionados aos direitos humanos é visível nas coleções publicadas ao longo da década de 1990. Na coleção de Francisco de Assis Silva (1990), ainda que sem a mesma densidade na exposição de conteúdos e com ausência da reprodução das declarações de direitos, aparecem textos interessantes sobre a situação da mulher na História. 
Em meados da década de 1990, alguma inovação começa a aparecer no conteúdo das coleções didático-escolares dedicadas ao ensino de História, devido, sobretudo, à emergência da História Nova (GATTI JÚNIOR, 2004), com preocupações sobre a história do cotidiano e das mentalidades, o que se evidencia na introdução da observação sobre o modo de vida burguês, as ideias disseminadas por esse novo grupo social, os relatos de dificuldade de usufruir de direitos básicos pelos estratos mais pobres da população, as diferenças do modo de viver dos norte-americanos e dos soviéticos, bem como os movimentos de rebeldia e contestação da década de 1960, tais como, pelos direitos civis, contra o racismo, pelos direitos das mulheres, contra a escola tradicional etc., conforme pode ser observado na coleção didática de autoria de Ricardo Dreguer e Eliete Toledo, em 1995, intitulada "História: cotidiano e mentalidades", publicada pela Atual Editora. Todavia, a inclusão desses conteúdos se fez em detrimento da exposição mais detalhada dos conteúdos das declarações de direitos ao longo da História.

Entre o final da década de 1990 e o início da década de 2000, foram publicados, pelo governo brasileiro, os Parâmetros Curriculares Nacionais para o Ensino Fundamental (1998) e os Parâmetros Curriculares Nacionais para o Ensino Médio (2000), ficando evidente que os direitos humanos animaram, de modo fundamental, o conteúdo de ambos os documentos legais, dando sequência ao espírito presente nos textos tanto da Constituição da República Federativa do Brasil de 1988 quanto da Lei de Diretrizes e Bases da Educação Nacional de 1996. 


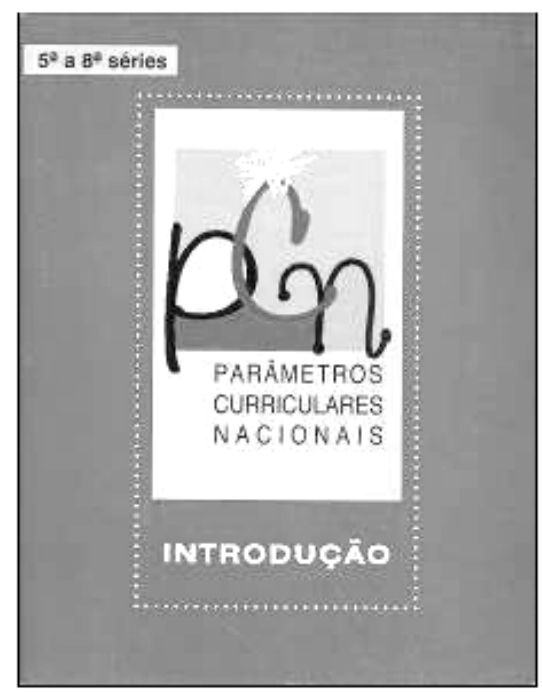

Capa da $2^{a}$ edição da Introdução aos Parâmetros Curriculares Nacionais, Terceiros e quarto Ciclos do Ensino Fundamental, publicada em 2001 , pela Secretaria de Educação Fundamental do Ministério da Educação, a partir de documento original publicado em 1998.

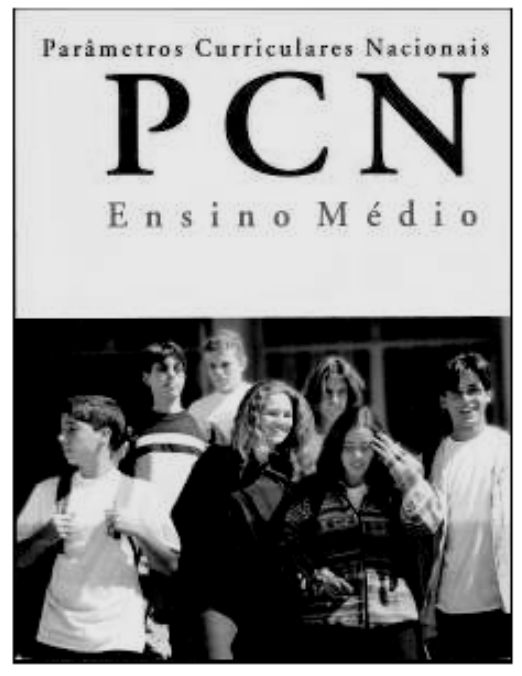

Capa dos Parâmetros Curriculares Nacionais: ensino médio, publicado em 2002, pela Secretaria de Educação Média e Tecnológica do Ministério da Educação, a partir de documento original publicado em 2000. 
Paradoxalmente, essa é uma época quando os livros didáticos começam a rivalizar com as coleções vinculadas a programas de ensino completos lamplamente utilizados nas escolas particulares, e também, em alguns sistemas municipais de ensino e, quase sempre, apostilados), percebendo-se, devido aos limites rigorosos quanto ao número de páginas destes materiais, um esvaziamento do conteúdo histórico disseminado, com consequências visíveis para aquele relacionado ao conhecimento dos direitos humanos, da paz e do pacifismo, pois, ainda que os temas tradicionais apareçam, lluminismo, Independência dos Estados Unidos, Revolução Francesa, o número de páginas é bastante reduzido para o tratamento desses conteúdos, com perda de densidade, bem como com a ausência da reprodução de documentos fundamentais, ainda que se perceba esforço de manter concisão no conteúdo, por exemplo, no material do Sistema de Ensino Integral (2007), o que foi agravado pela inexistência de alguma disciplina especificamente direcionada à formação da cidadania, dada que, na nova concepção, todas as disciplinas, em colaboração, o seriam.

Todavia, há exceções, tais como a obra "Nova História" (ARRUDA, 2004), na qual o conteúdo de História Moderna e Contemporânea ocupa 796 páginas, contemplando os principais fatos históricos vinculados à emergência dos direitos humanos. Trata-se, porém, de uma obra que, por sua dimensão e densidade, provavelmente, possa ser mais utilizada no Ensino Superior que no Ensino Médio brasileiros. 


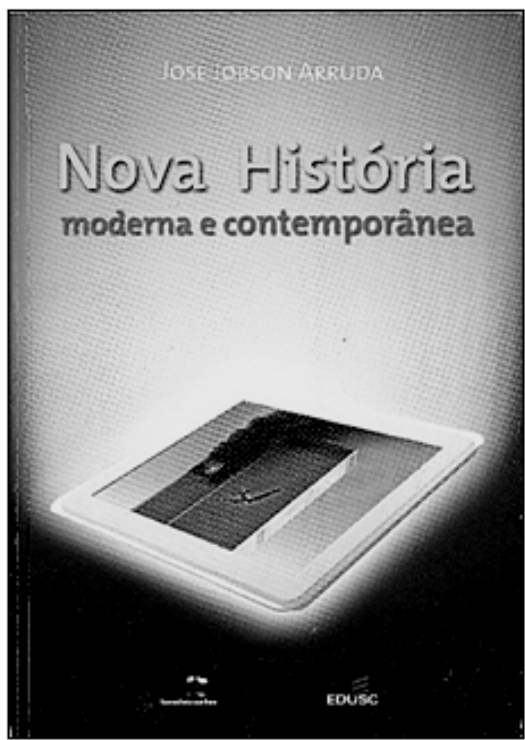

Capa da obra intitulada Nova História: moderna e contem-porânea, com autoria de José Jobson Arruda, publicado em Bauru/SP, pela EDUSC, 2004.

\section{Considerações finais}

Depreende-se do exame dos conteúdos veiculados, nos livros didáticos examinados, que eles expressavam, nas décadas de 1940 a 1970, de um lado, proximidade com a disseminação de um ideário moral cristão, de corte católico em que o amor e o respeito ao próximo são ideais-chave da formação moral no âmbito escolar e visam à formação do bom cristão.

Por outro lado, porém, no mesmo período, constatou-se, também, em algumas obras, proximidade de um ideário liberal laico, com busca da formação do bom cidadão, no qual era recurso importante de veiculação de um ideário relacionado à preservação da vida e ao patriotismo, por meio da paz e do pacifismo; a apresentação de ideias relacionadas à doutrina dos Direitos Humanos, tais como as contidas na Declaração de Independência dos Estados Unidos (1776), na Declaração dos Direitos do Homem e do Cidadão (1789), na Declaração Universal dos Direitos Humanos (1948). Trata-se, porém, de um conteúdo disseminado com restrições, tendo em vista que, entre 1964 e 
1985, para alguns historiadores e, entre 1967 e 1979, para outros, vivia-se, no Brasil, sob a égide de uma ditadura de caráter civil e militar.

Na década de 1980, momento de abertura política no Brasil e de redemocratização, houve iniciativas originais e críticas no que se refere aos livros didáticos escolares, em especial naqueles da área de Organização Social e Política do Brasil (OSPB).

Porém, no período seguinte, compreendido entre as décadas de 1990 a 2000, no plano legal da educação nacional, houve a extensão da adesão à Doutrina do Direitos Humanos e à Educação para a Paz, abrangendo mais amplamente conteúdos relacionados aos direitos civis, ao lado dos direitos sociais, o que pode ser notado em documentos normativos estatais, tais como a nova Lei de Diretrizes e Bases da Educação brasileira (1996), mas, sobretudo, com a publicação, a partir de 1998, dos Parâmetros e Diretrizes Curriculares Nacionais, o que, infelizmente, devido à diluição desse conteúdo por todas as matérias de ensino, resultou no quase desaparecimento da temática da literatura didático-escolar brasileira.

Assim, ao final deste pequeno arrazoado, fica-se com a percepção geral de que os conteúdos históricos relacionados ao conhecimento dos direitos humanos não se apresentaram no passado recente e, ainda, carecem de apresentar, na atualidade, a consistência necessária nos livros didáticos de História brasileiros.

Porém, em face das exigências contidas nos documentos legais brasileiros e da importância do domínio desses conteúdos sobre os direitos humanos, sobre a paz e sobre o pacifismo, para a construção da democracia política, há ainda um longo caminho a percorrer no ensino escolar brasileiro.

\section{Notas}

1 Texto em português, modificado e ampliado, em relação ao trabalho apresentado em inglês na sessão paralela intitulada Textbooks and War in the Twentieth Century durante a International Standing Conference for the History of Education 36, no Institute of Education da University of London, em 23 de julho de 2014.

2 A esse respeito, observar a diferenciação entre finalidades de objetivos (ideais) e realidade pedagógica contida em Chervel (1990) e ampliada por Julia (2011). 
3 No que se refere aos movimentos em torno do controle estatal sobre os conteúdos disseminados em manuais e livros didáticos, pode ajudar na compreensão do fenômeno a leitura de Gatti Júnior (2004), enquanto, no que se refere às interfaces entre os programas de ensino e a ação dos docentes no âmbito escolar, poderia ser útil a leitura de Gatti (2013).

4 Ver a este respeito: Moschini; Costa; Mussumeci (1970)

5 Dadas o controle estatal e as exigências legais da época, consta das páginas iniciais da obra - seguinte "Este livro foi aprovado pela Comissão Nacional de Moral e Civismo - Processo CNMC 0062/78 com homologação publicada no Diário Oficial da União de 9 de novembro de 1978".

6 Os mesmos autores, na coleção "Nossa História" (FARIA; MARQUES, 1984), reapresentaram essas temáticas, com enriquecimento de conteúdo e melhoria considerável da exposição didática, com inserção de ilustrações e mapas que não existiam na coleção anterior.

\section{Referências}

ARRUDA, José Jobson. Nova História moderna e contemporânea. Bauru/SP: EDUSC; São Paulo: Bandeirantes, 2004.

ÁVILA, Fernandes Bastos de. Pequena enciclopédia de moral e civismo. Rio de Janeiro: Ministério da Educação e Cultura. 1967.

BETTO, Frei. OSPB: introdução à política brasileira. 16. ed. São Paulo: Ática: 1992.

BRASIL. Constituição dos Estados Unidos do Brasil (aprovada em 18 de setembro de 1946). Rio de Janeiro: Aurora, 1953.

Portaria Ministerial $\mathrm{n}^{\circ}$ 1045, de 14 de dezembro de 1951. Aprova os planos de desenvolvimento dos programas mínimos do curso secundário e respectivas instruções metodológicas. In: BRASIL. Ministério da Educação e Saúde. Serviço de documentação. Programas do ensino secundário. São Paulo: Nacional, 1952. p. 172-185.

Portaria Ministerial $\mathbf{n}^{\circ}$ 966, de 2 de outubro de 1951. Aprova programas para $\bigcirc$ curso secundário. In: BRASIL. Ministério da Educação e Saúde. Serviço de documentação. Programas do ensino secundário. São Paulo: Nacional, 1952. p. 50-52.

Constituição da República Federativa do Brasil laprovada em 5 de outubro de 1988). Disponível em: http://www.planalto.gov.br/ccivil_03/ constituicao/constituiçãocompilado.htm. Acesso em: 3 maio 2014. 
Lei $\mathbf{n}^{\circ} \mathbf{9 . 3 9 4}$ de 20 de dezembro de 1996. Estabelece as Diretrizes e Bases da Educação Nacional. Disponível em: http://www.planalto.gov.br/ ccivil_03/leis/19394. htm. Acesso em: 3 maio 2014.

Ministério da Educação. Secretaria de Educação Básica. Parâmetros Curriculares

Nacionais 5a a 8a séries. 1998. Disponível em: http://portal.mec.gov.br/index. php? $\mid$ temid=859\&catid=195: seb-educacao -basica\&id=12657: parametros-curriculares-nacionais-5o-a-8o-series\&option =com_content\&view=article. Acesso em: 3 maio 2014.

Ministério da Educação. Secretaria da Educação Básica. Parâmetros Curriculares

Nacionais para o Ensino Médio (2000). Disponível em: http://portal.mec.gov.br/seb/ arquivos/pdf/14_24.pdf. Acesso em: 3 maio 2014.

Sistema de ensino integral. $7^{\circ}$ ou $8^{\circ}$ ano. Campinas (SP): Editora CDE Comércio de Material Didático, 2007. (4 vs. Ensino fundamental).

CHERVEL, André. História das disciplinas escolares: reflexões sobre um campo de pesquisa. Teoria \& Educação, Porto Alegre. n. 2, p. 177-229, 1990. (Tradução Guacira Lopes Louro).

DREGUER, Ricardo; TOLEDO, Eliete. História: cotidiano e mentalidades. São Paulo: Atual, 1995.

FARIA, Ricardo de Moura; MARQUES, Adhemar Martins. Nossa história. Belo Horizonte: Lê, 1984.

FARIA, Ricardo de Moura; MARQUES, Adhemar Martins. Síntese de história. Belo Horizonte: Lê, 1979. (v. 2, História Geral).

FARIA; Ricardo de Moura; DUARTE, Gleuso Damasceno; MARUM, Antonio. Estudos sociais. 3. ed. Belo Horizonte: Lê, 1979. (4 v.).

GATTI JÚNIOR, Décio. A escrita escolar da história: livro didático e ensino no Brasil ( 1970 1990). Bauru (SP): Edusc; Uberlândia (MG): Edufu, 2004.

GATTI, Giseli Cristina do Vale. A escola e a vida na cidade: o Gymnásio Mineiro de Uberlândia (1929-1950). Uberlândia (MG): Edufu, 2013.

JULIA, Dominique. A cultura escolar como objeto histórico. Revista Brasileira de História da Educação, São Paulo, n. 1, p. 9-43, 2001. (Tradução Gizele de Souza).

LUCCl, Elian Alabi. TDMC: trabalho dirigido de moral e civismo (2. grau). 3. ed. São Paulo: Saraiva, 1979. 
MATTA, Ary da. História geral (História moderna e contemporânea). 3. ed. São Paulo: Companhia Editora Nacional, 1956.

MOSCHINI, Felipe; COSTA, Otto; MUSSEMECI, Victor. Moral e civismo: ensino de primeiro grau (8ª Série). São Paulo: Editora do Brasil, 1970.

MUSSUMECI, Victor. História geral (Quarta série ginasial). São Paulo: Editora do Brasil, 1959

PILETTI, Claudino. OSPB. (Totalmente reformulada). 30. ed. São Paulo: Ática, 1993.

SILVA, Francisco de Assis. História geral. 2. ed. São Paulo: Moderna, 1990. Iv. 2, História moderna e contemporânea).

SILVA, Francisco Teodoro da; CUNHA, Tarcísio C. Almeida. Curso de educação moral e cívica. (Para o ensino de $2^{\circ}$. grau). 7. ed. Belo Horizonte: Lemi, 1977.

MELLO, Astrogildo de; [SILVA; Raul de Andrade]; GARCIA, Rosendo Sampaio. História geral. (Segunda série, curso ginasial). 7. ed. São Paulo: Editora do Brasil, 1950.

ONU. Declaração Universal dos Direitos Humanos. (10 de dezembro de 1948). Disponível em: http://www.dudh.org.br/wp-content/uploads/2014/12/dudh.pdf. Acesso em: 3 241 maio 2014

SOUZA, Alcindo Muniz de. História geral. (Segunda série ginasial). 13. ed. São Paulo: Companhia Editora Nacional. 1951.

TÔRRES, João Camillo de Oliveira. Educação moral e cívica. (Organização política do Brasil pela Constituição de 1969). 6. ed. Belo Horizonte: Júpiter. 1971.

Prof. Dr. Décio Gatti Júnior Universidade Federal de Uberlândia Faculdade de Educação Grupo de Pesquisa em História e Historiografia da Educação Brasileira Bolsista de Produtividade em Pesquisa do CNPq | Nível 1 C Beneficiário do Programa Pesquisador Mineiro da FAPEMIG E-mail | degatti@ufu.br 
Profa. Dra. Giseli Cristina do Vale Gatti Universidade de Uberaba Programa de Pós-Graduação em Educação Grupo de Pesquisa em História e Historiografia da Educação Brasileira Beneficiária do Edital Universal da FAPEMIG E-mail | giseli.vale.gatti@gmail.comr

Recebido 2 fev. 2015 Aceito $1^{\circ}$ abr. 2015 